Didáctica. Lengua y literatura

ISSN: 1130-0531

\title{
Explotación didáctica de la poesía en el aula de español como lengua extranjera. Propuesta de trabajo para el nivel avanzado de las EEOOII a partir de un poema de Clara Janés
}

\author{
Raquel Lanseros Sánchez¹; María Remedios Sánchez García ${ }^{2}$
}

Recibido: 18 de febrero de 2017 / Aceptado: 9 de junio de 2017

Resumen. En el aula de español como lengua extranjera (ELE), la poesía es una de las herramientas más útiles con las que cuenta el profesor en el proceso de enseñanza-aprendizaje de la lengua diana. Por un lado, los poemas son textos literarios breves, que suponen una unidad de significación completa y ofrecen un inmenso corpus de construcciones sintácticas, elementos léxicos y multiplicidad semántica. Por otro lado, contienen códigos culturales que favorecen el aprendizaje del entorno del español. Este trabajo presenta una propuesta didáctica dirigida al nivel avanzado de las Escuelas Oficiales de Idiomas (EEOOII), a raíz de un poema de Clara Janés. Partiendo del poema, se presentan una serie de actividades de profundización lingüística y de comprensión lectora, así como iniciativas de fomento de la lectura. De igual modo, se pretende acercar a los alumnos de español como lengua extranjera la figura de Clara Janés, una de las más reconocidas representantes de la poesía española contemporánea. Palabras clave: Poesía; ELE; Clara Janés; educación literaria; EEOOII.

\section{[en] Didactic Exploitation of Poetry in the Classroom of Spanish as a Foreign Language. Proposal of Work for the Advanced Level of the Official Schools of Languages from a Poem by Clara Janés}

\begin{abstract}
In the classroom of Spanish as a foreign language, poetry is one of the most useful tools available to the teacher in the teaching-learning process of the target language. On the one hand, poems are short literary texts, which assume a unit of complete meaning and offer an immense corpus of syntactic constructions, lexical elements and semantic multiplicity. On the other hand, they contain cultural codes that favour the learning of the Spanish environment. This paper presents a didactic proposal directed to the advanced level of the Official Schools of Languages, following a poem by Clara Janés. Starting from the poem, a series of activities of linguistic deepening and reading comprehension are presented, as well as initiatives to promote reading. Similarly, it is intended to bring the figure of Clara Janés to the students of Spanish as a foreign language, one of the most renowned representatives of contemporary Spanish poetry.
\end{abstract}

Keywords: Poetry; Spanish as a foreign language; Clara Janés; literary education; Official Schools of Languages.

\footnotetext{
1 Departamento de Didáctica de la Lengua y la Literatura. Universidad de León (España) E-mailırlans@unileon.es

2 Departamento de Didáctica de la Lengua y la Literatura. Universidad de Granada (España) E-mail reme@ugr.es
} 
[fr] Exploitation didactique de la poésie dans la salle de classe d'espagnol comme langue étrangère. Proposition de travail pour le niveau avancé des Écoles Officielles de Langues à partir d'un poème de Clara Janés

Résumé. Dans la salle de classe d'espagnol comme langue étrangère, la poésie est l'un des outils les plus utiles qui possède l'enseignant dans le processus d'enseignement-apprentissage de la langue cible. D'une part, les poèmes sont des textes littéraires courts, qui représentent une unité complète de sens et offrent un vaste corpus de structures syntaxiques, des éléments lexicaux et la multiplicité sémantique. D'autre part, ils contiennent des codes culturels qui favorisent l'environnement d'apprentissage de l'espagnol. Cet article présente une proposition éducative pour le niveau élevé des Écoles Officielles des Langues, à partir d'un poème de Clara Janés. Basées sur le poème, une série d'activités d'approfondissement linguistique et de la compréhension de la lecture, ainsi que des initiatives pour promouvoir la lecture sont présentés. De même, on vise à amener aux étudiants d'espagnol comme langue étrangère la figure de Clara Janés, l'une des représentantes les plus reconnues de la poésie espagnole contemporaine.

Mots-clés: Poèmes ; espagnol comme langue étrangère ; Clara Janés ; éducation littéraire ; niveau avancé des Écoles Officielles des Langues.

Sumario. 1. Introducción. 2. Justificación de la propuesta didáctica. 3. Nivel de aplicación. 4. Aclaraciones metodológicas. 5. Propuesta didáctica a partir de "No sé", un poema de Eros, de Clara Janés. 5.1. Planteamiento inicial. 5.2. Actividades. 5.3. Criterios de evaluación. 5.4. Procedimientos de evaluación, instrumentos y registros. 6. Conclusiones. 7. Bibliografía.

Cómo citar: Lanseros Sánchez, R.; Sánchez García, M. R. (2018) Explotación didáctica de la poesía en el aula de español como lengua extranjera. Propuesta de trabajo para el nivel avanzado de las EEOOII a partir de un poema de Clara Janés, Didáctica. Lengua y literatura, 30, 105-115.

\section{Introducción}

La poesía es una de las principales herramientas didácticas con las que cuenta el profesor en el aula de lengua extranjera. Por su creatividad, su uso estético del lenguaje y su multiplicidad de sentidos, la poesía supone una fuente imprescindible de aprendizaje, tanto en el ámbito lingüístico como en el cultural. "Debemos reivindicar el gran potencial de la poesía en una enseñanza de ELE comunicativa y personalizada, precisamente por su eficacia expresiva y por fomentar la creatividad del individuo" (López Toscano, 2013, 115).

Las nuevas tendencias de enfoque comunicativo dentro de la metodología de enseñanza de lenguas extranjeras remarcan la extrema importancia del aprendizaje del entorno cultural que rodea a una lengua e impregna el acervo común de sus hablantes nativos. La poesía, en el caso del español como lengua extranjera, proporciona una oportunidad única de acceder a esos presupuestos culturales de los países donde se habla -España y América Latina- puesto que se trata de un uso específico del idioma, normalmente culto, aunque también puede ser coloquial, que carece de los filtros específicos de los manuales de enseñanza del idioma.

El conocimiento de la cultura que rodea a la lengua extranjera que desea adquirirse, y más concretamente de su literatura, ayuda a desarrollar una valoración más positiva de ella, además de hacer al estudiante partícipe de conocimientos que 
favorecen su proceso de aprendizaje. Este refuerzo de la ligazón afectiva del alumno hacia la lengua que estudia se produce de una forma decidida mediante el uso y análisis de la poesía en el aula, puesta que esta potencia inferencias estéticas de índole universal que facilitan el funcionamiento de la memoria y la individualización del vocabulario y las estructuras lingüísticas.

Además, la exposición a los textos poéticos genera una respuesta emocional muy favorecedora del proceso de aprendizaje, alejándolo de las propuestas gramaticalistas conservadoras, más frías y rutinarias. Es innegable además, "la necesidad de una revalorización de su potencial como fuente de inspiración para la creación de actividades comunicativas, a la vez que integradoras de las cuatro destrezas lingüísticas" (Albaladejo, 2007, 2).

Entre las razones que justifican la introducción de poemas en la clase de ELE podemos mencionar:

- Facilitan un acercamiento práctico al lenguaje connotativo, metafórico e imaginativo de la lengua española.

- Dan cuenta de la historia acaecida en cada periodo en el país de origen del poema, bien sea España o Hispanoamérica, a través de la figura del autor y de las expresiones y giros propios de su tiempo.

- Son por lo general textos breves que permiten su temporización dentro de una o dos sesiones de una unidad didáctica, agilizando así el ritmo de aprendizaje del aula.

- Proporcionan una visión elemental de la literatura escrita en español, mediante la inclusión de varios autores que conforman un panorama inicial.

\section{Justificación de la propuesta didáctica}

Hemos seleccionado un poema de la poeta Clara Janés para efectuar nuestra propuesta didáctica de desarrollo y puesta en práctica en el aula. Se trata de familiarizar al alumnado con el lenguaje poético y, más allá, con el universo literario de Clara Janés, quien ha sido capaz de aunar en su producción la esencialidad y la búsqueda de la verdad, configurando un territorio en el que las tierras y las lenguas se funden en un espacio común de conocimiento.

Para la selección de este poema, hemos tenido en cuenta el especial significado simbólico dentro de su trayectoria vital y poética. "No sé", es un poema muy lírico de resonancias eróticas, que indaga en uno de los grandes universales poéticos: la pasión amorosa. Además, uno de sus versos está escrito en inglés, lo cual nos conecta con otra brillante faceta de Clara Janés, su trabajo como traductora desarrollado durante años, que ha vertido al español poetas como Vladimir Holan, Jaroslav Seifert, Ramos Rosa, etc. Es importante que los estudiantes tomen conciencia del proceso de traducción de poesía, porque ello les ayudará en su propia construcción de la lengua diana, español para extranjeros, en este caso. El texto alude además a la espiritualidad, el misterio y el sentido de lo transcendente, aspectos estos muy presentes en la poesía de Clara Janés y una de las claves primordiales para comprender su obra poética. 


\section{Nivel de aplicación}

La poesía aúna, dentro de los géneros literarios, todas las funciones comunicativas que explicitara Roman Jakobson (1963). Su inclusión en el aula de español para extranjeros de las EEOOII es imprescindible para dotar a los alumnos de una formación lingüística que incluya contenidos socioculturales y desarrollo de la educación emocional en la lengua de aprendizaje. El propio Marco común europeo de referencia para las lenguas (MCER) lo explicita: "Los estudios literarios cumplen muchos más fines educativos, intelectuales, morales, emocionales, lingüísticos y culturales que los puramente estéticos" $(2002,60)$.

Conscientes de que su comprensión requiere unos conocimientos previos amplios de la lengua española, hemos situado nuestra propuesta didáctica en el Nivel Avanzado de la Enseñanza de Idiomas de Régimen Especial, del idioma español para extranjeros. Se trata del nivel más alto, dentro de la enseñanza de idiomas de régimen especial, y es, por tanto, el nivel más adecuado para la explotación didáctica del poema propuesto. La presente propuesta didáctica puede ser implementada en el primer o segundo curso del nivel avanzado, dependiendo del criterio personal del profesor y el grado global de conocimiento de cada grupo determinado.

Según el Real Decreto 1629/2006, de 29 de diciembre, por el que se fijan los aspectos básicos del currículo de las enseñanzas de idiomas de régimen especial reguladas por la Ley Orgánica 2/2006, de 3 de mayo, de Educación; la definición del nivel avanzado es la siguiente: "El Nivel avanzado presentará las características del nivel de competencia B2, según este nivel se define en el Marco Común Europeo de Referencia para las Lenguas" (MCER).

El nivel avanzado tiene como finalidad capacitar a los alumnos para utilizar el idioma con soltura y eficacia en situaciones habituales y más específicas que requieran comprender, producir y tratar textos orales y escritos conceptual y lingüísticamente complejos, en una variedad de lengua estándar, con un repertorio léxico amplio aunque no muy idiomático, y que versen sobre temas generales, actuales o propios del campo de especialización del hablante.

\section{Aclaraciones metodológicas}

La metodología empleada tendrá un enfoque comunicativo y velará por la potenciación y el desarrollo de las cuatro destrezas comunicativas: comprensión oral, comprensión escrita, expresión e interacción oral y expresión e interacción escrita. Se tratará en todo momento de estimular una comprensión profunda del texto a través de la lectura, como afirman López Valero y Encabo Fernández:

El objetivo prioritario de la educación literaria deberá partir de la creación y fomento de su propia intertextualidad como elemento básico de su competencia literaria, que le permitirá establecer asociaciones entre la obra literaria percibida y otras manifestaciones artísticas, a partir de la actualización de sus propios conocimientos y del uso de estrategias y recursos múltiples, de manera que la relación establecida entre ése y otros muchos textos le sirva para construir de forma significativa su propio conocimiento y desarrollar su espíritu crítico (2013, 32-33). 
La aproximación a la didáctica de la poesía ha de ser interactiva e incluir los siguientes elementos:

- Enfoque comunicativo.

- Clases prácticas, ágiles e innovadoras.

- Interpretación conjunta de los textos.

- Interacción continua profesor-alumno.

- Aprendizaje cooperativo.

- Trabajo escrito e iniciación a la escritura creativa.

- Debate abierto sobre los múltiples sentidos y significaciones de la poesía.

- Análisis de los elementos culturales presentes.

- Uso de las TIC (plataformas, páginas web, blogs, webquests, etc.) para recabar y ampliar información.

En cuanto a la aplicación de la poesía al aula, es importante que el profesor no actúe tan solo como transmisor de información, sino que se convierta en investigador de la propia acción educativa que está poniendo en práctica. De este modo, pasará a ser mediador entre su propia teoría y la praxis educativa implementada.

\section{Propuesta didáctica a partir de "No sé", un poema de Eros, de Clara Janés}

\subsection{Planteamiento inicial}

El poema pertenece al libro Eros, publicado en 1981. Es importante realizar como paso inicial una contextualización histórico-literaria de la poeta cuyo poema seleccionado vamos a ir trabajando. Por ello, días antes de comenzar la actividad, deberemos proporcionar a los alumnos algunos enlaces donde buscar información sobre la poeta y su obra.

Para el día del comienzo de la actividad didáctica con el poema "No sé", les habremos pedido que traigan redactada una pequeña biografía de la autora, en la que incluyan lo más representativo de su vida y su obra.

Comenzaremos la actividad leyendo en grupo unas cuantas biografías de la poeta escritas por los propios alumnos. El profesor aclarará aquellos detalles o aspectos tanto de su vida como de su obra poética que hayan podido pasar desapercibidos o no hayan sido comprendidos correctamente.

Una vez familiarizados con la figura del autor, procedemos a la lectura individual y grupal de su poema "No sé".

\section{NO SÉ}

Soy hermosa y mi piel es suave

y el viento del mar me devuelve rocío

de tiernas tersuras.

Mi cabello perfumo y adorno de áurea madreselva

y mi pecho es redondo y casi virginal. 
Tuve un amante que ensalzó mis caderas y mi forma de amar intensa y silenciosa. Podría ser aún como un río de luz en tus brazos.

No sé qué te retiene, si furtivo, he visto un destello de ardor en tu gesto al pasar.

Can I go forward when my heart is here?

No conozco la astucia, no soy como la hoja del chopo que en oruga se oculta y arracima antes de dar su tierno cuerpo al viento, soy clara y sin pudor, soy entera y tajante, y no sé seducir.

\subsection{Actividades}

Los alumnos comenzarán leyendo en voz baja el poema "No sé", fijándose especialmente en las palabras, las construcciones gramaticales, sus imágenes y las sensaciones que los versos les provocan.

El libro al que pertenece el poema "No sé" se titula Eros. Se interrogará a los alumnos sobre el significado de esta palabra y se les pedirá que apunten sus ideas sobre ella.

A continuación, buscarán en el diccionario la palabra "eros", fijándose especialmente en su origen. En español hay muchas palabras de origen griego, sobre todo en determinados campos como la medicina. Se pedirá a los alumnos que investiguen y localicen otras tres palabras españolas de origen griego. Las compartirán oralmente en el aula con el resto de sus compañeros, explicando su significado actual en español y el significado de la palabra originaria en griego clásico. Escribirán una redacción de doscientas palabras expresando su propia concepción de "eros".

La poesía de corte erótico y amoroso ha sido siempre muy abundante a lo largo de la historia de la literatura. Se invitará a los alumnos a reflexionar por qué creen que esto es así y cuál es el impulso humano universal que subyace. Además, se les pedirá su opinión sobre por qué creen que es tan común y poderosa la necesidad de cantarle al amor y a la sensualidad.

Después, se pedirá a los alumnos que busquen en el diccionario las palabras que no comprendan. Una vez cerrados los diccionarios, y buscadas todas las palabras desconocidas, tratarán de escribir su propia definición de las siguientes palabras: rocío, tersura, áurea, madreselva, virginal, ensalzar, furtivo, destello, ardor, astucia, chopo, oruga, arracima, pudor, tajante.

Seguidamente, reescribirán los siguientes versos tratando de encontrar un sinónimo para cada una de las palabras subrayadas:

Tuve un amante que ensalzó mis caderas y mi forma de amar intensa y silenciosa.

Podría ser aún como un río de luz en tus brazos. 
A continuación, reflexionarán sobre el resultado del ejercicio anterior, para intentar clarificar qué ha ocurrido al haber sustituido las palabras subrayadas por otras sinónimas. Reflexionarán sobre si ha cambiado mucho o no la estrofa del poema. Asimismo, dilucidarán si los cambios han sido mayores en el significado o en la estética del poema (ritmo, musicalidad, belleza, etc.).

El poema está escrito íntegramente en primera persona. Se preguntará a los alumnos por qué creen que la poeta la ha elegido para su construcción. Meditarán sobre si la primera persona aporta mayor significación o intensidad al poema, razonando su respuesta.

En el antepenúltimo verso aparece el adjetivo "clara", que coincide con el nombre de la poeta.

soy clara y sin pudor,

Los alumnos debatirán sobre si ello es intencionado o solo fruto de la casualidad, y también hasta qué punto creen que el poema es autobiográfico, exponiendo las razones en las que se basan para defender su opinión.

La poeta utiliza un verso en inglés: "Can I go forward when my heart is here?" Se les pedirá a los alumnos que lo traduzcan al español (pidiendo ayuda a algún compañero o compañera en el caso de no saber inglés). Se debatirán las razones que, según ellos, han impulsado a Clara Janés a utilizar un verso en inglés. También se opinará sobre si ese verso suma significación al poema, o, por el contrario, carece de sentido.

Los alumnos investigarán sobre el origen del verso en inglés "Can I go forward when my heart is here?". Se les preguntará si es un verso de Clara Janés o se trata de una cita que ella utiliza para ampliar la significación y profundidad de "No sé".

Como habrán ya podido descubrir, el verso es una cita de William Shakespeare. Está incluida en su obra Romeo y Julieta, concretamente en el Acto 2, Escena 1, y es el propio Romeo quien lo afirma. A la luz de esto, se interrogará a los alumnos sobre el nuevo alcance de significación que adquiere el poema y sobre el motivo por el cual la autora utiliza una cita de Romeo y Julieta.

En una de las obras literarias más populares en España, La Celestina, escrita a finales del siglo XV y popularizada en el siglo XVI, aparecen también dos amantes desdichados cuya historia guarda puntos en común con Romeo y Julieta, aunque la española se escribió con un siglo de anterioridad. Se pedirá a los alumnos que averigüen de quiénes se trata.

La Celestina es en realidad el nombre popular con el cual se conoce este libro, titulado originalmente Tragicomedia de Calisto y Melibea. Se preguntará a los alumnos por qué creen que eran tan comunes en la época las historias de amantes desdichados, así como cuáles eran, en su opinión, los condicionantes sociales que impedían la libre realización de su amor.

Se pedirá a los alumnos que busquen en Internet un extracto de La Celestina que ejemplifique la presión ejercida sobre los jóvenes amantes y la desdicha de éstos que anticipa la tragedia final. Lo compartirán con sus compañeros y escucharán atentamente los escogidos por ellos a su vez.

Clara Janés es, además de poeta, una relevante traductora a quien debemos la versión en español de obras de importantes poetas como Vladimír Holan o Jaroslav Seifert, entre muchos otros. Los alumnos reflexionarán sobre el hecho de la traducción 
poética, y sobre cuáles creen que son las principales dificultades que se encuentra un traductor o traductora de poesía.

Se les pedirá que traduzcan a su idioma materno los versos de "No sé" que más te hayan gustado. Compartirán con sus compañeros las sensaciones experimentadas durante el proceso de traducción. Explicarán si las mayores dificultades encontradas fueron léxicas, rítmicas, fónicas, razonando y argumentando su respuesta.

Para finalizar, se les propondrá una actividad optativa. Si les ha gustado "No sé", pueden buscar información sobre Eros, el libro al que pertenece el poema de Clara Janés, y compartirla en clase con sus compañeros. Pueden contarles en qué año se publicó, qué ha dicho la crítica de él, de cuántas partes se compone, etc. Pueden también seleccionar otro poema del libro que les guste y traerlo a clase para leerlo en voz alta.

\subsection{Criterios de evaluación}

El tratamiento especial que merece la poesía en el aula requiere que su aplicación didáctica no sea evaluable del mismo modo que el resto de contenidos gramaticales o léxicos. De ser así, perdería gran parte del atractivo que posee para el alumno. Hay que recordar que la meta final no es aprender de memoria la biografía de un autor ni una lista de vocabulario, sino interpretar todos los posibles sentidos que tiene el lenguaje utilizado artísticamente y abrir la mente al mundo cultural que subyace bajo las palabras del idioma en curso de aprendizaje.

Los criterios de evaluación del nivel avanzado de español como lengua extranjera incluyen las competencias propias del nivel para cada una de las cuatro destrezas: comprensión oral, comprensión escrita, expresión e interacción oral y expresión e interacción escrita.

Sin embargo, debemos tener siempre presente que la inclusión de la poesía en el aula no es una propuesta didáctica gratuita, sino muy enriquecedora. Y precisamente a causa de su especial carácter de delectación estética, consideramos que sería contraproducente proceder con el mismo esquema evaluativo aplicable al resto de unidades didácticas del curso.

De este modo, los criterios de evaluación particulares para esta propuesta didáctica serían independientes y estarían únicamente basados en el poema seleccionado y en las actividades realizadas. Como ejemplo, los siguientes ítems pueden ser utilizados por el profesor para medir el rendimiento y la implicación de los alumnos en la propuesta didáctica de aplicación de la poesía al aula, puntuando cada uno de ellos como muy logrado, satisfactorio o no logrado.

1. ¿El estudiante muestra interés hacia la poesía española a través de Clara Janés?

2. ¿Reconoce las características y los rasgos identificativos de la poesía de Clara Janés?

3. ¿Mejora su comprensión lectora y su apreciación literaria con el desarrollo de la propuesta?

4. ¿Se observa un aprendizaje progresivo de las distintas habilidades comunicativas?

5. ¿Es capaz de llegar a una comprensión profunda del poema elegido? 
6. ¿Logra entender el significado de las palabras por su contexto?

7. ¿Mediante la lectura comprende el texto planteado en clase y es capaz de ver la intertextualidad que de él se desprende?

8. ¿Participa activamente en los debates suscitados con la aplicación didáctica del poema?

9. ¿Es capaz de expresarse con propiedad utilizando todo lo aprendido?

10.¿Se observa una actitud positiva hacia la potenciación de la creatividad en el aula?

11. ¿Es capaz de valorar los contenidos culturales y las propuestas estéticas contenidas en la poesía de Clara Janés?

El presente cuestionario de evaluación es para uso interno del profesor, que podrá ampliarlo o modificarlo según las necesidades específicas de su grupo-clase. Es aconsejable rellenarlo a la finalización de la propuesta didáctica, tras el desarrollo del poema, para de este modo ser capaz de analizar mejor el rendimiento de cada uno de los alumnos.

Por tanto, se trata de una acción didáctica de carácter específico, en la cual no todos los contenidos han de ser evaluables, sino más bien ejercicios instrumentalizados, un incentivo extra para que el estudiante se sumerja en la cultura de la lengua objeto de aprendizaje, así como en su musicalidad y su potencialidad estética. Este tratamiento más distendido potenciará sin duda el atractivo que ejerce la poesía en el marco de enseñanza-aprendizaje del español como lengua extranjera.

\subsection{Procedimientos de evaluación, instrumentos y registros}

Utilizaremos una serie de instrumentos de evaluación y de registro que pasamos a detallar a continuación, no sin antes mencionar algo que para nosotros resulta fundamental, como bien explicita Quiles Cabrera, "el mediador debe fijar los parámetros en función de los objetivos específicos para cada bloque de tareas, siempre guiados a través de unas pautas centradas en el aprender y formuladas desde una concepción formativa y nunca prescriptiva" (2012: s/p). A partir de ahí, las herramientas fundamentales son:

La Encuesta de detección de ideas previas sobre el tema que vamos a abordar nos permite recoger las ideas del alumnado, el grado de conocimiento de la obra y los posibles errores conceptuales. Constituye el primer paso en la práctica docente.

El Diario de clase nos servirá para tener control sobre las actividades realizadas en clase, las tareas para casa (lectura de la obra, trabajo sobre la misma), así como para recoger aquellos imprevistos que se hayan podido producir durante la actividad. Cualquier incidencia o reflexión sobre el proceso deberá ser registrado en él.

Cuaderno de notas donde anotamos los resultados de los ejercicios realizados y las tareas encomendadas. Nos permite apuntar información para llevar a cabo la evaluación continua.

Otras actividades de evaluación pueden consistir en la lectura y comentarios de los medios de comunicación, debates, trabajo personal, actividades de expresión oral en grupo. Las utilizaremos dentro del proceso de evaluación continua y como procedimientos de evaluación sumativa. 
Cuestionarios de autoevaluación y de coevaluación, que nos ayudarán a detectar el grado de satisfaccción del alumnado con la propuesta didáctica. Asimismo, es muy importante disponer de un cuestionario de evaluación propio, que deberá ser respondido una vez que la propuesta haya sido implementada en el aula, con vistas a asegurarnos una mejora de los aspectos cuyo proceso haya resultado menos satisfactorio, así como un ahondamiento en aquellos que más provecho hayan permitido extraer a los alumnos de la aplicación en el aula de la propuesta didáctica. Algunas de las preguntas del cuestionario podrían ser:

- ¿Qué es lo que mejor ha funcionado de las actividades realizadas en esta propuesta didáctica?

- ¿Qué es lo que más ha gustado del poema?

- ¿Son capaces los estudiantes de identificar los rasgos propios de la poesía de Clara Janés?

- ¿Profundizar en la poesía ayuda a los estudiantes a comprender mejor nuestra cultura?

- ¿Se han asimilado los conceptos de cohesión, coherencia y adecuación tratados?

- ¿Los debates realizados han contribuido a acercar posturas y a fomentar la tolerancia?

- ¿Las actividades de expresión oral ayudan a la evolución de los aspectos fónicos, gramaticales y léxicos de los estudiantes?

- ¿Han participado activamente los estudiantes en el desarrollo de la propuesta didáctica?

- ¿Hay algo más que deberíamos haber hecho?

\section{Conclusiones}

Consideramos la poesía como una herramienta pedagógica indispensable en el aula de español como lengua extranjera. Su presencia en la programación didáctica del nivel avanzado de las EEOOII sería muy beneficiosa para el proceso de aprendizaje global del alumnado. Por un lado, se trata de un contacto lingüístico pluridimensional y altamente motivador. Por otro, posee una enorme potencialidad intrínseca para desarrollar la competencia comunicativa de los estudiantes, tanto en su vertiente lingüística como pragmática.

Para el presente trabajo de aplicación didáctica de la poesía de Clara Janés al nivel avanzado del aula de español como lengua extranjera, hemos elegido un poema, con el cual hemos construido una propuesta didáctica no evaluable en términos convencionales, que constaría de tres a cuatro horas académicas, dependiendo del ritmo de aprendizaje de los estudiantes.

El enfoque comunicativo, predominante en la actualidad en las metodologías de enseñanza de lenguas extranjeras, subraya la importancia del uso de la poesía en el aula, como parte efectiva de la necesaria realia ${ }^{3}$ de la que hay que dotar al alumnado.

El término realia se refiere, en el ámbito de la metodología de enseñanza de lenguas extranjeras, al uso consistente de objetos reales y tangibles en el aula. Dicha práctica abarca también los textos auténticos de comunicación lingüística, no diseñados expresamente para la docencia. Los poemas son un inmejorable ejemplo de ello, máxime si tenemos en cuenta su vertiente de transmisión cultural y de valores. 
Para aprovechar todas sus potencialidades, la explotación en el aula debe realizarse tanto desde la vertiente lingüística (gramatical, léxica y fónica) como desde la vertiente pragmática (sociolingüística y cultural). De este modo, la necesaria aplicación didáctica de la poesía al aula podrá ofrecer resultados óptimos en aprendizaje y en motivación.

El poema seleccionado para trabajar con el alumnado de español como lengua extranjera nos ha parecido adecuado desde el punto de vista gramatical, semántico y cultural. Pensamos que acercar la poesía a los estudiantes a través de un autor contemporáneo puede ser una fuente extra de motivación para el aprendizaje de la lengua diana. La poesía, en la enseñanza de español como lengua extranjera, no está suficientemente explotada, a pesar de sus inmensas posibilidades pedagógicas. Nuestra intención es construir un puente entre este género literario y los estudiantes de español, y pensamos que el modo más efectivo de conseguirlo es mediante la implementación en el aula de propuestas didácticas significativas y motivadoras, con un alto potencial de transmisión cultural y valor educativo.

\section{Bibliografía}

Albaladejo García, María Dolores (2007): "Cómo llevar la literatura al aula de ELE: de la teoría a la práctica", MarcoELE. Revista de Didáctica ELE, 5, 1-51.

Instituto Cervantes (2006): Plan Curricular del Instituto Cervantes. Niveles de referencia para el español, Vol. 3, Madrid, Biblioteca Nueva.

Jakobson, Roman (1963): Essais de linguistique générale, Paris, Minuit.

Janés, Clara (1981): Eros, Madrid, Hiperión.

López Toscano, Joaquín (2013): "El verso si breve dos veces bueno: La poesía como herramienta en la enseñanza de ELE", Molina Muñoz, P. J. (coord.), Actas de las $V$ Jornadas de Formación para Profesores de Español en Chipre, Nicosia, Centro de Lengua - Universidad de Chipre, 115-126.

López Valero, A. y E. Encabo Fernández (2013): Fundamentos didácticos de la lengua y la literatura, Madrid, Editorial Síntesis.

MCER, Marco común europeo de referencia para las lenguas: aprendizaje, enseñanza y evaluación (2002): Madrid, MECD.

Quiles Cabrera, María Carmen (2012): "Entre pinceles y libros: textos para un enfoque intertextual e interdisciplinar en el aula de lengua", Álabe, 6, 1-19.

Real Academia Española (2014): Diccionario de la lengua española, $23^{\mathrm{a}}$ ed., Madrid, Espasa. 